\title{
NOTAS SOBRE LA LENGUA ESPAÑOLA HABLADA EN MADRID
}

Cercana ya la fecha en que el "Proyecto de Estudio Coordinado de la Norma Lingüística Culta de las Principales Ciudades de Iberoamérica y de la Península Ibérica" va a cumplir sus veinticinco años de existencia (nació oficialmente el 5 de agosto de 1964 en Bloomington, Indiana, durante el II Simposio del PILEI [Programa Interamericano de Lingüística y Enseñanza de Idiomas]), parece conveniente reflexionar sobre algunos de sus logros en nuestro país. Si bien el Proyecto surgió, como nos cuenta su artífice primero, Juan M. Lope Blanch, en El estudio del español hablado culto. Historia de un proyecto (págs. 9-19), para corregir los tópicos y errores con los que se describía habitualmente el español de América, pronto se extendió, por recomendación de la Asociación de Academias de la Lengua Española en su IV Congreso (Buenos Aires, diciembre de 1964), al habla culta de algunas ciudades españolas, en concreto a Madrid, y posteriormente a Sevilla (el intento inicial de estudiar el habla de Barcelona no llegó a cuajar).

Desde el principio, gracias al entusiasmo y esfuerzo de los profesores Manuel Alvar y Antonio Quilis, el Consejo Superior de Investigaciones Científicas, y en concreto su Departamento de Geografía Lingüística, impulsaron decisivamente el Proyecto, hasta el punto de que los textos básicos con los que se ha elaborado la mayoría de las encuestas (y a partir de ellas, los estudios) los editó el C.S.I.C. bajo el título Cuestionario para el estudio coordinado de la norma lingüistica culta de las principales ciudades de Iberoamérica y de la Península Ibérica en 1971 (el tomo III, dedicado al Léxico), en 1972 (el tomo II, 1, que se ocupa de la Morfosintaxis) y en 1973 (el tomo I, dedicado a Fonética y Fonología). Aunque la realización del Proyecto ha sido muy irregular en las diversas ciudades donde se lleva a cabo, en Madrid 
se inició bastante pronto: entre el 15 de septiembre y el 24 de diciembre de 1968 se realizaron las primeras encuestas (457), que comenzaron a transcribirse a finales de diciembre de ese mismo año; sin embargo, habrán de pasar más de doce años hasta que se publican algunas de esas encuestas: son $M$. Esgueva y M. Cantarero quienes editan El habla de la ciudad de Madrid. Materiales para su estudio (1981). Diez años antes habían visto la luz las encuestas de la Ciudad de México, y dos años antes las de Caracas y Santiago de Chile. No obstante, a partir de este año de 1981 la regularidad y rigor de las publicaciones del equipo del C.S.I.C. es muy notable, pues en el mismo 1981 se editan también otras encuestas: José C. de Torres Martínez, Encuestas léxicas del habla culta de Madrid; y posteriormente los estudios parciales sobre ese rico material que ha llevado años recopilar y ordenar. Así, La concordancia gramatical en la lengua española hablada en Madrid, de Antonio Quilis (1983), El pronombre personal sujeto en la lengua española hablada en Madrid, de Emilia V. Enríquez (1984), Los pronombres "le", "la", "lo" y sus plurales en la lengua española hablada en Madrid, de Antonio Quilis, Margarita Cantarero, M. a José Albalá y Rafael Guerra (1985), y Repertorio léxico obtenido de las "Encuestas léxicas del habla culta de Madrid", de Victoria Marrero y M. a José Quilis (1986). Éstas son sólo las monografías largas, publicadas en forma de libro, dentro de la colección "La norma lingüística culta de la lengua española hablada en Madrid" ; pero hay, lógicamente, otros trabajos, más breves, debidos casi en su totalidad a Antonio Quilis, sobre la frecuencia de fonemas y esquemas acentuales, y sobre galicismos, anglicismos, arabismos y helenismos [cfr. págs. 196-197 de la obra citada de Juan M. Lope Blanch para más detalles]. Y en curso de publicación y realización hay mucho más, de gran interés, de lo que da noticia Antonio Quilis en el informe recogido en el libro de Lope Blanch ya mencionado (págs. 197-199).

Los tres estudios citados en el párrafo anterior (que hacen los números 3,4 y 5 de la colección que nos ocupa) se caracterizan por el empleo de unos mismos datos y una idéntica metodología. En los tres casos se manejan encuestas realizadas a individuos de ambos sexos pertenecientes a cuatro generaciones: una primera, comprendida entre los quince y los veinticuatro años; una segunda, entre los veinticinco y los treinta y cinco años; una tercera, entre los treinta y seis y los cincuenta y cinco años; y una cuarta, desde los cincuenta y seis en adelante. Esta división en cuatro generaciones introduce un cambio respecto de las normas del Cuestionario (t. I, pág. xv) aplicado en otras ciudades, pues en él sólo se contemplan tres (no se incluían sujetos de edades inferiores a los veinticinco años); los investigadores del habla de Madrid han considerado interesante, sin embargo, estudiar también el comportamiento lingüístico de estos jóvenes por cuanto ello puede resultar 
significativo de las nuevas tendencias aún en formación. Por otro lado, las encuestas son de tres tipos: las dirigidas (la gran mayoría de las empleadas en estos tres estudios), que consisten en preguntas que hace el encuestador a los informantes sobre determinado tema; las espontáneas (donde dos informantes hablan libremente sobre lo que desean, sabiendo que su conversación se está grabando); y las secretas (en las que los informantes hablan libremente, sin saber que se les está grabando). Todos los estudios también van acompañados de un importante análisis estadístico, con numerosas tablas que resumen las principales variables manejadas (edad, sexo y tipo de encuesta) y los resultados obtenidos. Se aplica generalmente el llamado test de Pearson (y algún otro también en el estudio de Emilia V. Enríquez) para valorar el grado de ajuste entre la realidad observada y el modelo matemático empleado, con lo que las conclusiones obtenidas del análisis parecen siempre suficientemente contrastadas y fiables, muy alejadas ya de las apreciaciones subjetivas de otros estudios anteriores. Esto significa que al interés del trabajo sobre textos reales, del lenguaje hablado, se suma en estas monografías una metodología rigurosa, que permite alcanzar unos resultados de gran fiabilidad.

En La concordancia gramatical... Antonio Quilis hace un interesante análisis de 179 encuestas de una duración media de cuarenta-cincuenta minutos realizadas a 221 informantes, que presenta en dos partes: a) la concordancia nominal; y b) la concordancia verbal. Llama la atención en el primer grupo la concordancia del artículo, sobre todo en el caso de los sustantivos que comienzan con /á/, donde se registran ejemplos del tipo "Eso de que nos metan en una aula, no", "... ahora mismo era una agua nieve...", y "el deporte de la escopeta o del otro arma", que completan el estudio de Juan Martínez Marín, "Este agua y construcciones afines en español actual” (Lingüistica española actual, IV / 1 (1982), págs. 39-46). Destacan también en esta primera parte las concordancias entre los cuantitativos, como bastante, que concuerda en número con el resto de los elementos de la oración que están en plural ("...nosotros trabajábamos bastantes más que ellos"); como medio que se registra como adjetivo cuando en realidad es adverbio ("estoy media cansada"), o como adverbio cuando se trata de adjetivo ("una medio unidad"); y como demasiado ("No tiene tampoco demasiada buena fama el Profesor X"). Curiosas son asimismo las anomalías en la concordancia entre sustantivo y adjetivo (en lo que respecta al género y al número), que suponen un $47,75 \%$, y las que se producen con los nombres propios geográficos, aunque, como admite el autor, parecen poco relevantes ya que "la mayoría de las discordancias se producen por equivocación, por cruce de una idea con otra, por rectificar repentinamente lo que el hablante 
estaba diciendo o iba a decir, también por pérdida de /-s/ en algún caso, etc." (pág. 103).

En la segunda parte, dedicada a la concordancia verbal, se dedica gran atención a los casos de sujeto único o múltiple (págs. 49-72) y a la concordancia ad sensum (págs. 73-86). En este último caso se presentan datos relativos a las preferencias en el empleo del singular o del plural en los verbos según el sustantivo colectivo de que se trate; así, el verbo aparece con mayor frecuencia en singular con los sustantivos gente, juventud, pueblo, población y todo el mundo, mientras que se manifiesta en plural con mayoría o serie. Las construcciones atributivas son objeto también de un apartado interesante, que nos muestra la concordancia de estas construcciones cuando se presentan con elemento neutro o sin él ("lo que más leo es novelas francesas", "en la educación, lo fundamental son los conocimientos de base", "todo son tonterías", "pienso que burgueses es casi todo el mundo", "cariñoso conmigo son todos"), o con elemento cuantitativo ("el ochenta o noventa por ciento son cosas debidas a la sociedad", "cuarenta mil pesetas, en aquella época, era dinero").

Nos ha sorprendido, en esta segunda parte, el punto 9, dedicado a la concordancia de haber y hacer, que - como es sabido- suelen presentarse con muchísima frecuencia en amplias zonas del mundo hispanohablante en construcciones personales ("hubieron fiestas", "hicieron grandes heladas"). La norma culta de Madrid se ajusta, sin embargo, de acuerdo con este estudio, a la norma académica. Escribe así A. Quilis: "En nuestros materiales, de 2.384 construcciones registradas de este tipo, sólo tenemos dos que presenten construcción irregular, con haber: "Habian muchas injusticias sociales", "Habian programas...". Un caso en la primera generación informante masculino y otro, en la cuarta, informante femenino" (pág. 94). Por último, se dedica un apartado a la concordancia entre antecedente y consecuente (el relativo, el pronombre complemento, y el pronombre demostrativo).

En el análisis estadístico que completa el volumen, Quilis hace notar que los datos reunidos, contra lo que a priori cabría esperar, revelan que "curiosamente las generaciones que presentan un número de faltas mayor al esperado son las dos intermedias, mientras que la primera y la última, es decir, las formadas por los informantes más jóvenes y más viejos, respectivamente, cometen menos faltas de concordancia de las que cabría suponer" (pág. 124), y añade después: "Algo parecido a lo observado con el tipo de encuestas y la generación de los informantes ocurre con el sexo de estos últimos (cuadro I5). Los varones se equivocan relativamente más que las hembras, y esta diferencia no parece casual".

El número 4 de esta colección es una extensa monografía de Emilia V. Enríquez, El pronombre personal sujeto en la lengua española hablada en 
Madrid, cuya primera parte (130 páginas) se aleja del estilo de los otros títulos, ya que está dedicada íntegramente a una presentación teórica de la categoría de "persona" y de los pronombres. Tan sólo a partir de la página 131 se inicia el desarrollo de la investigación sobre las encuestas del habla culta de Madrid, siguiendo la metodología descrita más arriba. Este sistema de encuestas se revela, sin embargo, insuficiente en algunas ocasiones para dar cuenta de los usos de algunas formas, pues, por ejemplo, en una conversación en la que intervienen dos personas (el encuestador y el informante) hay lógicamente pocas posibilidades de que se presenten formas como vosotros o ustedes, ya que la referencia más común es unipersonal. Por otro lado, los resultados parecen también en otros momentos distorsionados por el modelo de la encuesta, como cuando se nos dice que usted se utiliza más que $t u ́$, lo que está en contradicción con el avance evidente del tuteo, señalado ya antes por muchos estudiosos. La autora es consciente de estos problemas y trata de explicarlos, aclarándole al lector el alcance real de las cifras que presenta: "Hay que destacar... que nuestro estudio se basa en el análisis de las formas personales del verbo con presencia o ausencia de un pronombre personal sujeto, a partir de lo cual obtenemos las frecuencias absolutas y relativas que manejamos en las pruebas estadísticas y que nos permitirán conocer el funcionamiento de estas formas. En este sentido, cuando afirmamos que, por ejemplo, usted se utiliza más que tú no hacemos sino poner de manifiesto que las formas verbales de tercera persona correspondientes a los usos de cortesía aparecen acompañadas del pronombre más frecuentemente de lo que lo hacen las formas de segunda persona." (pág. 147).

No obstante, los datos que arroja el análisis son de gran interés, porque después de estudios promenorizados sobre los tiempos, formas, frases y modos verbales, comprobamos que éstos no influyen significativamente en el comportamiento de los pronombres. Son básicamente tres los rasgos que definen el funcionamiento de estos elementos: el rasgo [ + humano]; el rasgo [ + determinado]; y el rasgo $[+$ contraste]. Con respecto al primer rasgo, resulta muy significativo, según se nos dice, que de un total de mil novecientos cinco verbos cuyo sujeto era un sustantivo, masculino o femenino, de carácter no-humano, sólo tres presenten el pronombre personal sujeto, lo que representa el $0,15 \%$ de presencias en este tipo de construcciones, y el $0,06 \%$ con respecto al total de cuatro mil ochocientos cincuenta y cuatro pronombres registrados. De forma paralela, se hace notar también la práctica inexistencia de ello en la lengua hablada, "que aparece expresado en dos únicos casos, de un total de mil trescientas sesenta posibilidades $(0,14 \%)$ y que supone el 0,04\% del total de las presencias obtenidas" (págs. 335-336). En cuanto al rasgo de [ + determinado] conviene resaltar que de cada cien casos con sujeto indeterminado apenas se encuentra uno con el pronombre 
expresado, lo que -además - conlleva una cierta pérdida de la indeterminación; y lo mismo ocurre cuando los pronombres se refieren a sustantivos colectivos. El tercer rasgo de interés es el de $[+$ contraste], que se percibe en las referencias a seres humanos, cuando los pronombres se manifiestan en la oración para establecer un determinado contraste (en un $90 \%$ de los casos), que está explícitamente marcado respecto de otro elemento implicado en el enunciado.

La monografía de Enríquez nos revela también la relación existente entre la aparición de las formas pronominales y determinada semántica verbal. Se nos indica, así, cómo aumenta el uso de los pronombres con verbos que suponen una estimación, valoración $\mathfrak{u}$ opinión de cualquier tipo; y asimismo, la vinculación que puede establecerse entre la aparición de estas formas con la oración compuesta, así como con el contexto lingüístico y extralingüístico. Lo que sí llama la atención en las conclusiones es la mayor frecuencia de aparición de las formas de cortesía; sorprende, así, encontrar esta afirmación en la página 340: "Las formas usted y ustedes son siempre las que muestran mayores frecuencias de uso, superándose siempre el setenta por ciento de presencias, resultando, además, las menos permeables a cualquier variación". Aunque la autora no quiere decir que se use más el pronombre de cortesía que el tuteo (aquí sólo se habla de la aparición de los pronombres junto a la forma verbal correspondiente, y parece que usted se presenta junto al verbo con mayor frecuencia que tú), quizá hubiera sido conveniente realizar un estudio del empleo de tú y usted con más datos (y con otro tipo de encuesta), pues se trata de uno de los fenómenos de cambio lingǘstico de mayor interés en el momento presente (no se cita, por ejemplo, el ensayo, realizado con encuestas, de Vidal Alba de Diego y Jesús Sánchez Lobato sobre esta alternancia en las jóvenes generaciones madrileñas: "Tratamiento y juventud en la lengua hablada. Aspectos sociolingüísticos", $B R A E$, LX, cuaderno CCXIX, enero-abril 1980, págs. 95-129, que -aunque no se restringe a la norma culta- podría haber sido elemento importante para contrastar los resultados de las encuestas examinadas por Enríquez). Y no se trata, desde luego, de que la autora no haya abordado este aspecto. En las páginas 195-196, por ejemplo, se refiere a las diferencias en el empleo de las formas de cortesía entre las generaciones más jóvenes y las más viejas, pero el propio modelo de las encuestas y las mediciones que tratan de hacerse impiden extraer conclusiones significativas. Así, leemos en estas páginas: "Se establece, pues, un claro enfrentamiento entre, por un lado, las dos generaciones más jóvenes, y por el otro, las dos generaciones de más edad, con diferencias significativas que superan, además, los veinte puntos, por lo que resultan ya de considerable interés. Esto implica no ya que el tratamiento de respeto es más habitual en las generaciones mayores 
(tal como nos indican, por otra parte, los totales absolutos de cada generación), sino que, además, los sujetos de más edad tienden a utilizar las formas usted y ustedes junto al verbo mucho más frecuentemente que las generaciones jóvenes".

El quinto volumen de la serie, del que son autores Antonio Quilis, Margarita Cantarero, M. ${ }^{\text {a }}$ José Albalá y Rafael Guerra, se dedica a otro aspecto apasionante de nuestra lengua actual: Los pronombres "le", "la", "lo" y sus plurales en la lengua española hablada en Madrid. Después de una sucinta presentación del estudio en el contexto del Proyecto sobre la norma culta y de unas referencias a las 110 encuestas analizadas, se nos ofrece una rápida (aunque suficiente para el propósito del volumen) visión de lo que se ha escrito sobre el leísmo, el laísmo y el loísmo. A continuación se pasa a un estudio pormenorizado de las apariciones de cada pronombre (con las funciones sintácticas que desempeña), al que siguen comentarios sobre algunas particularidades, como duplicaciones, reiteraciones, faltas de concordancia y formas lexicalizadas. Un amplio estudio estadístico y una relación de verbos con la forma pronominal átona que rigen, junto a las conclusiones y la bibliografía, cierran el libro.

La claridad expositiva y la pulcritud del análisis son rasgos de esta monografía que llaman poderosamente la atención; pero hay, además, material polémico o, al menos, sorprendente, que invita a continuar el estudio. Quien discrepe de algunas conclusiones habrá de demostrar, con datos de idéntica fiabilidad a los aportados aquí, las razones de su discrepancia; y no parece nada fácil, clada la abrumadora cantidad de variables empleadas. Aunque el habla de Madrid se ha asociado comúnmente a la ruptura de la norma etimológica en el empleo de le, la y lo, de este estudio se deduce lo contrario: "el 88,82 por 100 de las funciones de los pronombres átonos se ajustan a la norma etimológica" (pág. 207). Es comprensible que ello sea así con el loísmo, pues - tratándose de informantes cultos - no sorprende que sólo haya un $0,14 \%$ de presencias erróneas. Pero, ¿qué ocurre con el laísmo, y sobre todo con el leísmo? Conviene precisar que los autores de este libro llaman "norma etimológica" a lo que en otras ocasiones denominan también "norma etimológica-académica", con lo que el empleo de $l e(s)$ en función de objeto directo cuando el referente es persona masculina entra dentro de esa norma (aunque no es estrictamente, como se sabe, la etimológica, sino la variante aceptada por la Real Academia). De esta forma, se entiende que el leísmo, muy extendido en el habla de Madrid, y de otras zonas de la Península Ibérica (aquí se registra el empleo de $l e(s)$ como objeto directo en un $20,8 \%$ de todos sus usos [p. 208]), no se vea como fenómeno perturbador de la norma etimológica, que es, sin embargo, la predominante en otros lugares.

Mas el caso del laísmo es aún más sorprendente, pues éste es un rasgo 
que solemos asociar (aunque no como fenómeno exclusivo) con el habla de la capital de España. Los resultados de esta encuesta arrojan, no obstante, un índice de aparición muy escaso: "El empleo de $l a(s)$ como objeto indirecto tiene una frecuencia muy baja: representa el 5,71 por 100 del total de ocurrencias de $l a(s)$ y el 1,07 por 100 de la población total de los pronombres, siendo casi diez veces superior su referencia a persona que a cosa. Por ello se puede decir que el laísmo en el habla culta madrileña es poco significativo" (pág. 208). Los autores son conscientes de que esta afirmación parece algo desorbitada y tratan de explicarla con otros datos, que son los relativos a la alta frecuencia con que el fenómeno se produce con determinados verbos, tales como decir, dar, gustar, poner, contar, quitar, ver, etc. que, como se aprecia, son de uso muy común; y además, como se añade en la misma página 208: "el porcentaje con respecto al número de veces que el verbo rige $\operatorname{la}(s)$ es muy elevado; por ejemplo, con escribir, el 100 por 100 ; con decir, el 82 por 100; con gustar, el 80 por 100; con preguntar, el 63 por 100 , etc. Esto da la impresión de un laísmo que está lejos de ser general en el habla culta madrileña".

Otro aspecto de interés es la escasa (prácticamente nula) incidencia del sexo en el empleo de las formas pronominales, mientras que la edad sí es una variable de interés, pues en el caso concreto del laísmo (en los otros no) se aprecia una significativa tendencia a su favor por parte de los informantes más jóvenes (¿ ¿erán, así, el laísmo y el tuteo rasgos diferenciadores del habla culta de Madrid dentro de unas pocas décadas?). En cualquier caso, se insiste en repetidas ocasiones en la pervivencia del modelo etimológicoacadémico, e incluso en su reforzamiento en situaciones de vacilación: la hipercorrección de algunos hablantes que emplean $l e(s)$ como objeto directo con referente femenino, por ejemplo (véanse páginas 149-150). Con relación al leísmo, se comenta también la coexistencia casi en términos de igualdad de los empleos de $l o(s)$ y $l e(s)$ como objeto directo con referente masculino, lo que no deja de sorprender tampoco a hablantes de otras áreas, que "sentían" que el uso del leísmo en esos casos había acabado casi por completo con la norma etimológica: "Lo primero que llama la atención es cómo el uso de la formas $l e(s)$, con 459 ocurrencias y un 58,99 por 100 del total, no ha excluido al de la forma $l o(s)$, con 319 ocurrencias y un 41 por 100 . Este dato prueba la fuerza que tiene el empleo del sistema etimológico entre los hablantes cultos de Madrid" (pág. 147).

Resulta, pues, un estudio extremadamente revelador que invita, como se decía antes, a continuarlo, realizando más encuestas y extendiendo los informantes a otros niveles socioculturales y a otros ámbitos geográficos (las afueras de Madrid, por ejemplo). Quizá otro aspecto que podría considerarse en ese caso sería el examen más detenido de la presencia de estos pronom- 
bres átonos en estructuras del tipo se le, se la y se lo (y sus plurales), sobre las que existe tanta polémica (véase el segundo ensayo del librito de Santiago de los Mozos La norma castellana del español). En todo caso, este quinto título de la colección nos parece uno de los estudios mejor conseguidos y más sólidos del Proyecto, que dice mucho del esfuerzo y dedicación que están invirtiéndose en el C.S.I.C. en esta magna empresa. Con mucha esperanza e interés aguardamos, pues, la publicación de las monografías que están en prensa o en proceso de realización.

\section{M. a Angeles Álvarez Martínez Universidad de La Laguna}

\section{Bibliografía citada.}

Alba de Diego, Vidal, y Sánchez lobato, Jesús, "Tratamiento y juventud en la lengua hablada. Aspectos sociolingǘsticos”, $B R A E, \mathrm{I} . \mathrm{X}$, cuaderno CCIX, enero-abril 1980, págs. 95-129.

Cuestionario para el estudio coordinado de la norma lingüistica culta de las principales ciudades de Iberoamérica y de la Peniusula Ibérica, t. I, Fonética y Fonología, P.I.L.E.I. y C.S.I.C., Madrid, 1973 [xviii + 75 págs.]; t. II, 1, Morfosintaxis, P.I.L.E.I. y C.S.I.C., Madrid, 1972 [xiii +207 págs.] ; y t. III, Léxico, P.I.L.E.I. y C.S.I.C., Madrid, 1971 [viii + 221 págs.].

Enrfouez, Emilia V., El pronombre personal sujeto en la lengua española hablada en Madrid, Madrid, C.S.I.C., 1984 [393 págs.].

Esqueva, M. y Cantarero, M., El habla de la ciudad de Madrid. Materiales para su estudio, Madrid, C.S.I.C., 1981 [450 págs.].

Lope Blanch, Juan M., El estudio del español hablado culto. Historia de un proyecto, Universidad Nacional Autónoma de México, 1986 [217 págs.].

Los Mozos, Santiago de, La norma castellana del español, Valladolid, Ámbito, 1984 [99 págs.].

Marrero, Victoria, y Quilis, M. ${ }^{a}$ José, Repertorio léxico obtenido de las "Encuestas léxicas del habla culta de Madrid”, Madrid, C.S.I.C., 1986 [396 págs.].

Martfnez Marín, Juan, "Este agua y construcciones afines en español actual", Lingüistica española actual, IV / 1 (1982). págs. 39-46.

Quilrs, Antonio, La concordancia gramatical en la lengua española hablada en Madrid, Madrid, C.S.I.C., 1983 [130 págs.].

Quilis, Antonio, Cantarero, Margarita, Albalá, M. a José, y Guerra, Rafael, Los pronombres "le", "la", "lo" y sus plurales en la lengua española hablada en Madrid, C.S.I.C., Madrid, 1985 [216 págs.].

Torres Martínez, José C. de, Encuestas léxicas del habla culta de Madrid, Madrid, C.S.I.C., 1981 [xvi + 738 págs.]. 